\title{
POTENSI KAYU HASIL PEREMAJAAN KARET RAKYAT UNTUK MEMASOK INDUSTRI KAYU KARET Studi Kasus di Provinsi Sumatera Selatan
}

\author{
Potential Rubberwood of Smallholders' Replanting to Supply Timber Industry \\ A Case Study in South Sumatera Province
}

Cicilia NANCY, Dwi Shinta AGUSTINA, dan Lina Fatayati SYARIFA

Balai Penelitian Sembawa, Pusat Penelitian Karet

Jalan Raya Palembang - P. Balai KM 29, PO BOX 1127 Palembang 30001

Email : nancy_bps@yahoo.co.id,dwishinta_sbw@yahoo.com, lina_fsy@yahoo.com

Diterima tanggal 22 Oktober 2012 / Disetujui tanggal 25 Februari 2013

\begin{abstract}
Rubberwood as renewable product could be used to substitute natural forest wood. As the second largest natural rubber producing country after Thailand, Indonesia has not utilized the potential of rubberwood sources. The aim of this study was to determine the potential of rubberwood and its availability to supply timber industry in South Sumatra Province. The result of this study showed that potential of rubberwood in South Sumatra Province per year was about 1.7 million $\mathrm{m}^{3}$ or 1.1 million tonnes. Actual production of eight rubberwood factories in South Sumatra showed that of rubberwood that had been processed was only 18\% of the available rubberwood. When viewed from the source, around $74 \%$ of raw material came from smallholders. Some efforts should be made to maximize utilization of rubberwood from smallholder replanting area.
\end{abstract}

Keywords: rubberwood, replanting, smallholder

\section{Abstrak}

Kayu karet yang bersifat terbarukan (renewable) dapat dimanfaatkan untuk mensubstitusi kayu hutan alam. Sebagai negara produsen karet terbesar kedua setelah Thailand, Indonesia belum memanfaatkan potensi kayu karet yang ada. Penelitian ini bertujuan untuk mengetahui potensi kayu karet yang ada serta ketersediaannya untuk memasok industri kayu di Provinsi Sumatera Selatan. Dari hasil penelitian diketahui bahwa setiap tahun di tingkat Provinsi Sumatera Selatan, potensi kayu karet mencapai 1,7 juta $\mathrm{m}^{3}$ atau 1,1 juta ton. Produksi aktual kayu karet olahan yang dihasilkan oleh delapan pabrik kayu karet di Sumatera Selatan menunjukkan bahwa potensi kayu karet yang dimanfaatkan hanya $18 \%$ dari potensi kayu karet yang ada. Dilihat dari asal bahan baku, sebanyak $74 \%$ bahan baku berasal dari perkebunan karet rakyat. Perlu upayaupaya untuk memaksimalkan pemanfaatan kayu hasil peremajaan karet petani.

Kata kunci: kayu karet, peremajaan, perkebunan rakyat

\section{PENDAHULUAN}

Pasokan kayu untuk bahan baku industri yang berasal dari hutan alam semakin berkurang. Kayu yang berasal dari tanaman perkebunan yang bersifat terbarukan (renewable) seperti karet alam (Hevea brasiliensis, Muell Arg) dapat dimanfaatkan untuk mensubstitusi kayu hutan alam tersebut.

Kayu karet mempunyai beberapa keunggulan dibandingkan dengan kayu hutan alam, khususnya dari sisi warna dan teksturnya. Namun pemanfaatan kayu karet secara massal masih menghadapi beberapa kendala, seperti: a) seringkali kayu karet tidak dapat diambil karena akses jalan tidak tersedia (khususnya kayu karet dari areal perkebunan rakyat), b) rendemen kayu karet rendah, c) suplai kayu karet hanya tersedia pada musim-musim tertentu (khususnya musim kemarau/masa penyiapan lahan 
saat peremajaan kebun karet), dan d) lokasi pabrik pengolahan yang jauh dari lokasi kebun karet sehingga biaya transpor menjadi mahal dan memperkecil nilai ekonominya.

Di masa lampau, kayu karet hanya dimanfaatkan sebagai bahan bakar untuk pengasapan sit (RSS), bahkan untuk kebunkebun yang belum ada akses transportasi jalan, kayu karet hanya dibakar di kebun. Berdirinya pabrik pengolahan kayu karet sejak tahun 2000-an di sentra perkebunan karet rakyat diharapkan akan memberikan nilai tambah yang cukup berarti bagi petani karet yang akan meremajakan kebun karetnya. Untuk lokasi kebun yang dekat dengan pabrik kayu dan kondisi mutu kayu karetnya baik, hasil penjualan kayu karet dapat digunakan sebagai modal untuk membiayai kegiatan peremajaan. Apabila kayu karet dapat dimanfaatkan, ini akan sangat mendukung program Pembukaan Lahan Tanpa Bakar (PLTB), sekaligus mengurangi jumlah polusi yang diakibatkan pembakaran lahan.

Saat ini Indonesia merupakan negara penghasil karet alam terbesar setelah Thailand. Pada tahun 2010, total areal perkebunan karet di Indonesia mencapai 3,45 juta ha, dengan total produksi sekitar 2,3 juta ton. Karet rakyat memberikan kontribusi sebesar $85 \%$ dari total areal dan $80 \%$ dari total produksi. Namun demikian Indonesia belum memanfaatkan potensi kayu karet yang ada seperti terlihat dari nilai ekspor kayu karet yang sangat rendah dibandingkan dengan Malaysia (Tabel 1).
Pada Tabel 1 terlihat bahwa pada tahun 2009 nilai ekspor kayu karet Malaysia mencapai 2,3 Milyar US\$, padahal nilai ekspor karet sebagai produk utamanya hanya 1,47 Milyar US\$. Sementara di Indonesia nilai ekspor kayu karet hanya 7075 juta US\$ atau 1\% dari nilai ekspor karet alam yang mencapai 6 milyar US\$ pada tahun 2009. Dengan demikian kayu karet di Indonesia merupakan potensi sumber devisa yang belum mendapat perhatian baik dari pemerintah maupun investor. Berdasarkan hal tersebut, penelitian ini bertujuan untuk membahas tentang potensi kayu karet hasil peremajaan milik petani untuk mendukung pasokan industri kayu.

\section{BAHAN DAN METODE}

Penelitian dilaksanakan pada tahun 2011 dengan metode survei di beberapa kabupaten di Sumatera Selatan yang memiliki industri pengolahan kayu karet, yaitu Kabupaten Ogan Ilir, Kabupaten Muara Enim, Kabupaten Musi Banyuasin, OKU Induk, dan Kabupaten Musi Rawas. Data yang dikumpulkan meliputi data primer dan data sekunder. Data primer diperoleh melalui wawancara dengan pabrik pengolah kayu karet, supplier, dan petani sedangkan data sekunder diperoleh dari data statistik, laporan penelitian sebelumnya, dan jurnal. Produk olahan yang diamati meliputi veneer, kayu pertukangan (sawn timber), dan Medium Density Fibre $(M D F)$. Data yang diperoleh dianalisis secara deskriptif.

Tabel 1. Ekspor karet dan kayu karet Malaysia dan Indonesia, 2009

Table 1. Export of rubber and rubber wood of Malaysia and Indonesia, 2009

\begin{tabular}{lccc}
\hline & $\begin{array}{c}\text { Uraian } \\
\text { Description }\end{array}$ & Indonesia & Malaysia \\
\hline $\begin{array}{l}\text { Luas areal } \\
\text { Area }\end{array}$ & Juta ha (million Ha) & 3,2 & 1,4 \\
$\begin{array}{l}\text { Ekspor karet } \\
\text { Export of rubber }\end{array} \quad$ Nilai (Value) & & & \\
$\quad$ Volume (Volume) & juta US\$ (million US\$) & 6.023 & 1.473 \\
$\begin{array}{l}\text { Ekspor kayu karet } \\
\text { Export of rubberwood } \\
\text { Nilai (Value) }\end{array}$ & juta ton (million tons) & 2,3 & 0,7 \\
& juta US\$ (million US\$) & $70-75$ & 2.300 \\
\hline
\end{tabular}

Sumber (Source) : Ditjenbun, 2009 dan MRB, 2010 
HASIL DAN PEMBAHASAN

\section{Peremajaan dan Potensi Kayu Karet di Sumatera Selatan}

Provinsi Sumatera Selatan sejak tahun 2007 telah menjadi penghasil karet alam terbesar di Indonesia, kontribusinya terhadap produksi karet nasional juga semakin meningkat seperti terlihat pada Gambar 1. Pada tahun 2013, produksi karet Sumatera Selatan diharapkan mencapai 1 juta ton karet kering.
Karet alam merupakan salah satu komoditas unggulan Sumatera Selatan. Karet alam memberikan kontribusi yang sangat besar terhadap penerimaan non migas, di samping peran strategis lain yaitu sebagai sumber pendapatan masyarakat, menyerap banyak tenaga kerja dan perannya terhadap kelestarian lingkungan. Sejak meningkatnya harga karet dalam beberapa tahun terakhir, peran karet alam sebagai penggerak perekonomian masyarakat di daerah semakin dirasakan. Data pada tahun 2008 menunjukkan bahwa luas karet di Sumatera Selatan mencapai 0,66 juta hektar, hampir seluruhnya atau 93,5\% adalah karet rakyat (Tabel 2).

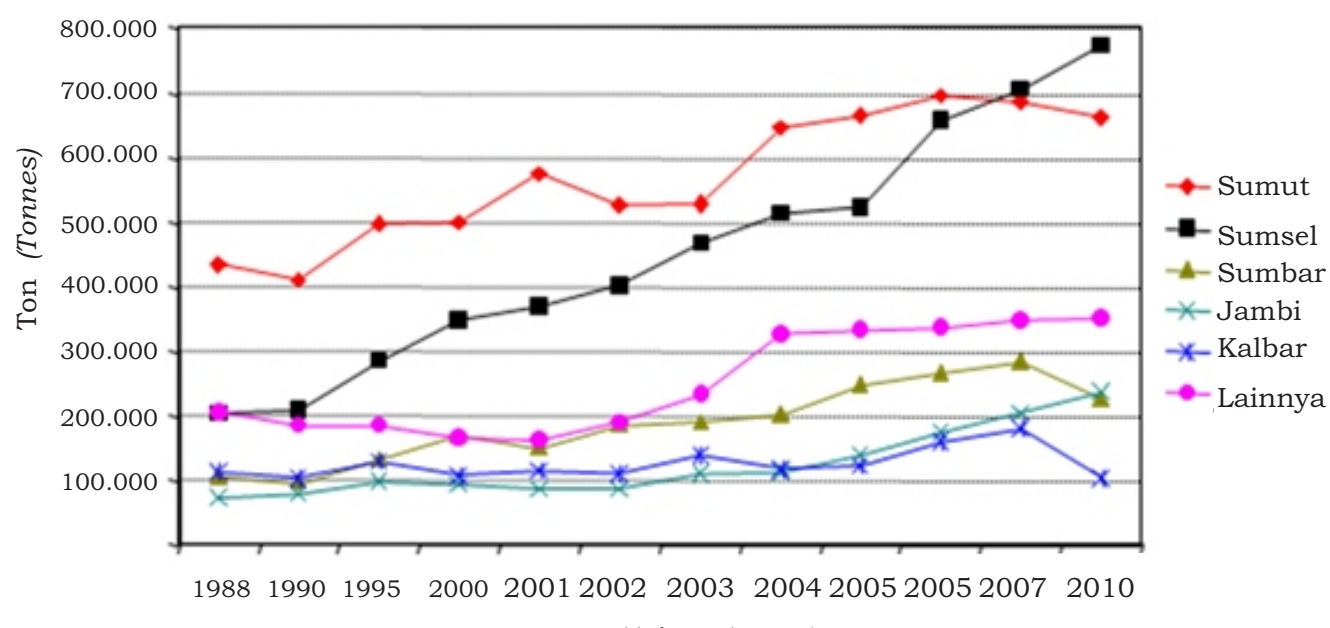

Gambar 1. Produksi karet di beberapa provinsi penghasil karet utama, 1988 - 2010

Figure 1. Rubber production of several main rubber producing provinces, 1988 - 2010

Tabel 2. Luas perkebunan karet di Provinsi Sumatera Selatan, 2008

Table 2. Area of rubber plantation in South Sumatera Province, 2008

\begin{tabular}{|c|c|c|c|c|c|}
\hline \multirow{2}{*}{$\begin{array}{c}\text { Uraian } \\
\text { Description }\end{array}$} & \multirow{2}{*}{$\begin{array}{c}\text { TBM } \\
\text { Immature } \\
\text { rubber plant } \\
\text { (ha) }\end{array}$} & \multirow{2}{*}{$\begin{array}{c}\text { TM } \\
\text { Mature } \\
\text { rubber plant } \\
\text { (ha) }\end{array}$} & \multirow{2}{*}{$\begin{array}{l}\text { TT/TR } \\
\text { Old/damaged } \\
\text { rubber plant } \\
\text { (ha) }\end{array}$} & \multicolumn{2}{|c|}{ Total } \\
\hline & & & & (ha) & $(\%)$ \\
\hline $\begin{array}{l}\text { Perkebunan Rakyat } \\
\text { Smallholder }\end{array}$ & 118.039 & 499.641 & 2.036 & 619.716 & 93,5 \\
\hline $\begin{array}{l}\text { Perkebunan Besar Negara } \\
\text { Government Estate }\end{array}$ & 1.838 & 19.476 & 359 & 21.673 & 3,3 \\
\hline $\begin{array}{l}\text { Perkebunan Besar Swasta } \\
\text { Private Estate }\end{array}$ & 5.095 & 15.337 & 966 & 21.398 & 3,2 \\
\hline Total & 124.972 & 534.454 & 3.361 & 662.787 & 100 \\
\hline Total & $(18,9)$ & $(80,6)$ & $(0,5)$ & (100) & \\
\hline
\end{tabular}

- Angka-angka dalam kurung merupakan persentase (Figures in brackets are percentage)

- Sumber (Source): Direktorat Jenderal Perkebunan, 2009 (Directorate General of Estate, 2009) 
Minat masyarakat menanam karet sangat tinggi. Hal ini tercermin dari luasnya penanaman karet yang dilakukan masyarakat. Hasil survei yang dilakukan pada tahun 2011 di 85 desa sentra karet di Sumatera Selatan menunjukkan bahwa di setiap desa pada tahun 2010 terdapat penanaman karet seluas 10 - 200 hektar atau rata-rata 40 ha per desa. Di desa tradisional karet, hampir seluruhnya (95\%) adalah areal peremajaan exkaret tua.

Sebagian besar kebun karet rakyat yang saat ini diremajakan adalah kebun karet tradisional yang sebagian besar berupa hutan karet, sehingga selain tanaman karet dijumpai tanaman hutan lainnya. Hasil wawancara dengan beberapa supplier (pembeli kayu karet) menunjukkan bahwa pada saat kebun karet diremajakan, potensi kayu karet sekitar 58\% dari volume kayu, sedangkan $42 \%$ sisanya adalah kayu jenis lain yang juga memiliki nilai ekonomi seperti pelawan, pelangas, leban, seru dan racuk.
Sementara pada perkebunan karet rakyat ex proyek atau yang sudah teratur seluruhnya adalah kayu karet.

Selanjutnya estimasi luas areal penanaman karet di Sumatera Selatan disajikan pada Tabel 3. Luas areal penanaman karet seluas 46 ribu ha, sebesar $62 \%$ atau 28.650 ha merupakan peremajaan dan selebihnya (38\%) adalah perluasan. Areal perluasan umumnya terdapat di wilayah-wilayah yang selama ini bukan merupakan daerah konvensional karet, seperti Kabupaten Lahat, OKU Timur, dan OKI.

Estimasi peremajaan di atas menggunakan skenario pesimis bahwa setiap tahun hanya terdapat 30 petani per desa yang meremajakan karetnya masingmasing seluas 1 ha. Apabila diasumsikan areal peremajaan hanya 30 ha/desa dan dari setiap hektar kebun karet tua dihasilkan kayu karet sebanyak 60 ton atau

Tabel 3. Estimasi luas pengembangan karet swadaya di Sumatera Selatan per tahun Table 3. Estimation area of self-help rubber development in South Sumatra per year

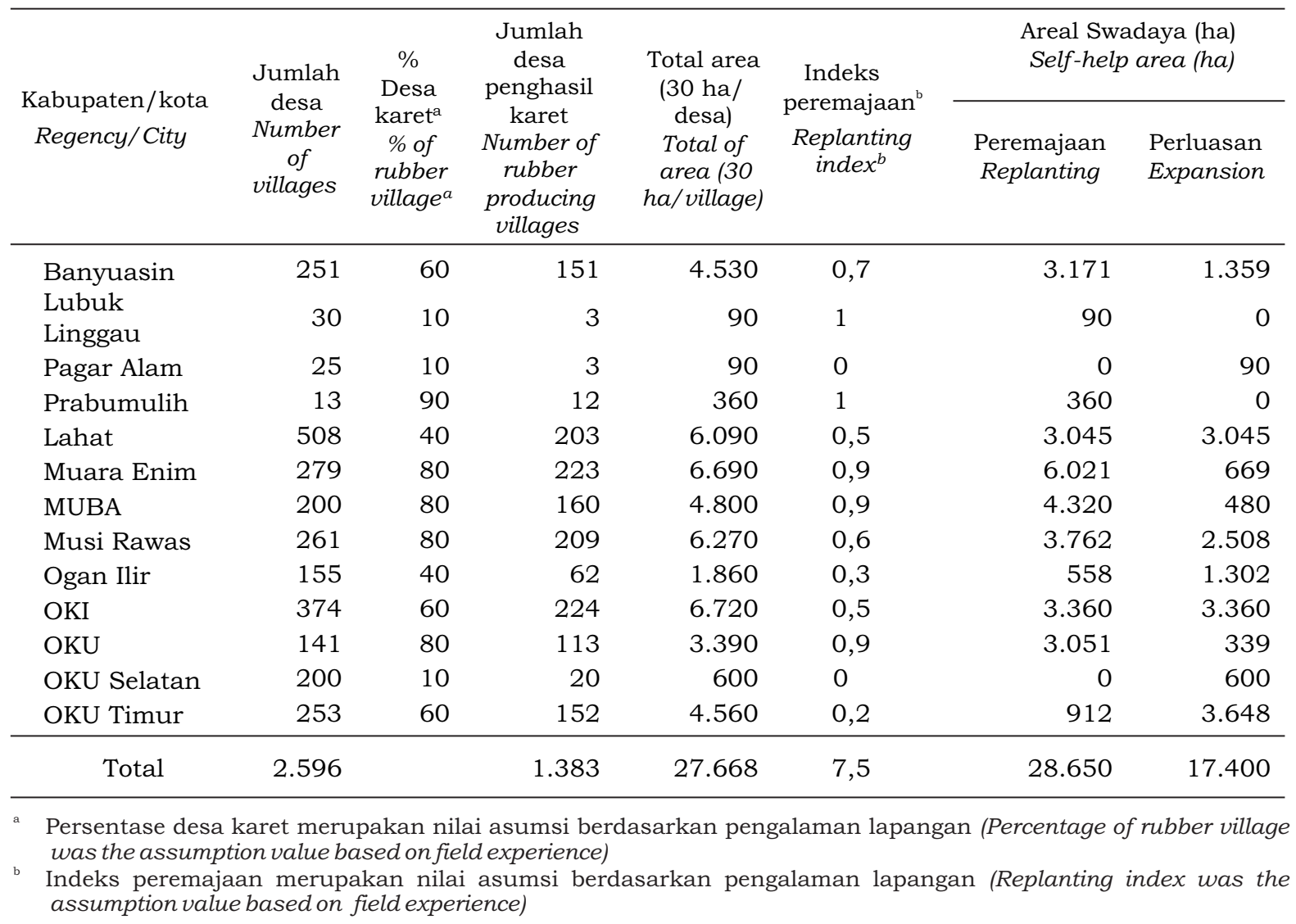


$40 \mathrm{~m}^{3}$, maka dari luas peremajaan seluas 28.650 ha akan diperoleh potensi kayu karet setiap tahun mencapai 1,7 juta $\mathrm{m}^{3}$ atau 1,1 juta ton. Tabel 4 menyajikan data produksi aktual kayu karet olahan yang dihasilkan dari delapan pabrik kayu karet yang ada di Sumatera Selatan, terlihat bahwa produksi kayu karet yang terolah hanya $18 \%$ dari potensi kayu karet yang ada.

Apabila dilihat sebarannya, maka pabrik di Sumatera Selatan tersebar di delapan kabupaten. Hal ini merupakan bagian dari strategi investor untuk menghindari kendala persaingan bahan baku.

Selanjutnya pada Tabel 5 disajikan data kapasitas olah industri pengolahan kayu karet dibandingkan dengan produksi aktual, ternyata realisasi produksi baru $56,5 \%$ dari kapasitas pabrik. Dilihat dari asal bahan baku, sebanyak $74 \%$ bahan baku berasal dari perkebunan karet rakyat.
CV. H yang mengolah sawntimber hanya beroperasi 10 bulan. Dari bulan Januari-Februari kegiatan pengolahan dihentikan sementara karena tidak memperoleh bahan baku, disebabkan pada musim hujan akses jalan terputus. Demikian juga PT. D, meliburkan karyawan dari bulan Nopember - Februari karena bahan baku kosong. Sementara pada kasus PT. F, sekalipun telah menyimpan stok dengan menampung bahan baku kayu karet cukup banyak pada musim kemarau (Juni-September), dari bulan Februari-Mei masih harus menghentikan operasional pabrik karena tidak tersedia bahan baku.

Kayu karet mempunyai nilai ekonomi yang tinggi jika lokasi kebun karetnya memiliki akses jalan yang baik yang dapat dijangkau oleh kendaraan truk dengan jarak kurang dari $150 \mathrm{~km}$ dari pabrik pengolahan kayu karet (disebut wilayah Ring 1). Pada wilayah Ring 1 biaya transportasi dari kebun ke pabrik kayu karet tidak terlampau mahal.

Tabel4. Produksi kayu karet olahan dibandingkan potensi bahan baku kayu karet di Provinsi Sumatera Selatan

Table 4. Production of processed rubberwood compared with the available potential raw material of rubberwood in South Sumatera Province

\begin{tabular}{|c|c|c|c|c|c|c|}
\hline \multirow[b]{2}{*}{$\begin{array}{l}\text { Pabrik } \\
\text { Factory }\end{array}$} & \multirow[b]{2}{*}{$\begin{array}{l}\text { Produk } \\
\text { Product }\end{array}$} & \multirow[b]{2}{*}{$\begin{array}{l}\text { Satuan } \\
\text { Unit }\end{array}$} & \multicolumn{3}{|c|}{$\begin{array}{c}\text { Produksi aktual pabrik } \\
\text { Actual production of factory }\end{array}$} & \multirow[b]{2}{*}{$\begin{array}{l}\text { Kabupaten } \\
\text { Regency }\end{array}$} \\
\hline & & & $\mathrm{m}^{3}$ & $\begin{array}{l}\text { Dari petani } \\
\text { Smallholder } \\
(\%)\end{array}$ & $\begin{array}{l}\text { Setara }^{1} \\
\text { Equal to } \\
\quad \text { (ha) }\end{array}$ & \\
\hline PT. A & veneer & $\mathrm{m}^{3}$ & 20.000 & 50 & 500 & Ogan Ilir \\
\hline PT. B & veneer & $\mathrm{m}^{3}$ & 25.000 & 50 & 625 & Musi Banyuasin \\
\hline PT. C & veneer & $\mathrm{m}^{3}$ & 23.000 & 100 & 1.150 & Musi Rawas \\
\hline PT. D & veneer & $\mathrm{m}^{3}$ & 2.500 & 100 & 120 & Muara Enim \\
\hline PT. E & triplek & $\mathrm{m}^{3}$ & 4.500 & 80 & 180 & Banyuasin \\
\hline PT. F & MDF & Ton & 70.000 & 70 & 1.700 & Ogan Ilir \\
\hline PT. G & $\mathrm{MDF}$ & Ton & 48.000 & 40 & 640 & Banyuasin \\
\hline CV. H & Sawn timber & $\mathrm{m}^{3}$ & 5.000 & 100 & 200 & OKU \\
\hline \multicolumn{5}{|c|}{$\begin{array}{l}\text { Areal peremajaan yang kayunya dipasok ke pabrik } \\
\text { Area of wood of replanting was supplied to the factory } \\
\text { Total areal peremajaan karet rakyat } \\
\text { Total area of smallholder's replanting }\end{array}$} & $\begin{array}{l}5.165 \\
(18 \%) \\
28650\end{array}$ & \\
\hline \multicolumn{7}{|c|}{$\begin{array}{l}-{ }^{1} \text { Rata-rata volume kayu karet dari perkebunan karet rakyat: } 40 \mathrm{~m}^{3} / \text { ha atau } 60 \text { ton } / \text { ha } \\
\text { Average rubberwood volume from Smallholder estate }: 40 \mathrm{~m}^{3} / \text { ha or } 60 \text { ton } / \text { ha } \\
\text { - }{ }^{2} \text { Rata-rata volume kayu karet dari kebun plasma: } 100 \mathrm{~m}^{3} / \mathrm{ha} \\
\text { Average rubberwood from plasma estate } \\
\text { - } \text { Rendemen (Recovery) veneer }=50 \%, \mathrm{MDF}=50 \% \text { dan Sawn timber }=25 \%\end{array}$} \\
\hline
\end{tabular}


Tabel 5. Kapasitas, produksi aktual dan sumber bahan baku untuk pabrik pengolahan kayu karet di Provinsi Sumatera Selatan

Table 5. Capacity, actual production and source of raw material for rubberwood processing factory in South Sumatera Province

\begin{tabular}{|c|c|c|c|c|c|c|c|}
\hline \multirow{2}{*}{$\begin{array}{l}\text { Pabrik } \\
\text { Factory }\end{array}$} & \multirow{2}{*}{$\begin{array}{l}\text { Produk } \\
\text { Product }\end{array}$} & \multirow{2}{*}{$\begin{array}{l}\text { Satuan } \\
\text { Unit }\end{array}$} & \multirow{2}{*}{$\begin{array}{c}\text { Kapasitas } \\
\text { pabrik } \\
\text { Factory } \\
\text { capacity }\end{array}$} & \multicolumn{2}{|c|}{$\begin{array}{l}\text { Produksi aktual } \\
\text { Actual production }\end{array}$} & \multicolumn{2}{|c|}{$\begin{array}{l}\text { Sumber bahan baku } \\
\text { Source of raw material }\end{array}$} \\
\hline & & & & $\left(\mathrm{m}^{3}\right)$ & $(\%)$ & $\begin{array}{c}\text { Perkebunan } \\
\text { besar } \\
\text { Big estate } \\
(\%)\end{array}$ & $\begin{array}{c}\text { Perkebunan } \\
\text { rakyat } \\
\text { Smallholder } \\
(\%)\end{array}$ \\
\hline PT. A (2008) & veneer & $\mathrm{m}^{3}$ & 50.000 & 20.000 & 40 & 50 & 50 \\
\hline PT. B (2005) & veneer & $\mathrm{m}^{3}$ & 40.000 & 25.000 & 63 & 50 & 50 \\
\hline PT. C (2007) & veneer & $\mathrm{m}^{3}$ & 45.000 & 23.040 & 51 & 0 & 100 \\
\hline PT. D (2009) & veneer & $\mathrm{m}^{3}$ & 5.000 & 2.500 & 50 & 0 & 100 \\
\hline PT. E (2009) & triplek & $\mathrm{m}^{3}$ & 6.000 & 4.500 & 75 & 20 & 80 \\
\hline PT. F (2003) & MDF & ton & 140.000 & 70.000 & 50 & 30 & 70 \\
\hline PT. G (2007) & $\mathrm{MDF}$ & ton & 100.000 & 48.000 & 48 & 60 & 40 \\
\hline CV. H (2002) & $\begin{array}{l}\text { sawn } \\
\text { timber }\end{array}$ & $\mathrm{m}^{3}$ & 6.000 & 4.500 & 75 & 0 & 100 \\
\hline \multicolumn{5}{|c|}{ Rata-rata } & 56,5 & 26 & 74 \\
\hline
\end{tabular}

- Sumber (source): Data Primer (Primary data)

- Angka-angka dalam kurung adalah tahun pendirian pabrik

Figures in brackets are the year of factory establishment

Sementara pada lokasi kebun yang relatif jauh dan belum ada prasarana jalan yang memadai, kayu karet tidak memiliki nilai ekonomi, dan biasanya kayu karet hanya dibakar di kebun.

Selanjutnya rantai pemasaran kayu karet dari tingkat kebun petani di desa sampai dengan ke tingkat industri pengolahan kayu karet disajikan pada Gambar 2. Bahan baku log sebagian besar $(85 \%)$ dipasok oleh supplier log, sisanya (15\%) diambil langsung oleh pabrik ke tingkat petani. Jumlah supplier tetap per pabrik sekitar 5-10 orang, adakalanya supplier mendapat pinjaman uang dari pabrik, namun karena pembayaran dari pabrik membutuhkan waktu $1-7$ hari, ada juga supplier besar yang justru mampu menutupi pembayaran untuk supplier kecil dengan mendapat marjin tertentu. Kerjasama antara pabrik dengan supplier umumnya tidak terikat kontrak, karena suplai karet sangat tergantung musim, sehingga apabila musim kemarau dikhawatirkan terjadi over supply, sebaliknya musim hujan bahan baku kosong.

Informasi adanya areal yang akan diremajakan biasanya berasal dari supplier, sementara proses pengurusan IPKTM (Izin Pemanfaatan Kayu pada Tanah Milik) sampai terbitnya SKAU (Surat Keterangan Asal Usul) di Dinas Kehutanan dan Kepala Desa umumnya diurus oleh pihak pabrik. Pada saat pengajuan IPKTM harus dilampirkan surat tanah, setelah diproses selanjutnya petugas meninjau lokasi kebun yang akan diremajakan.

\section{Permasalahan Pemanfaatan Kayu Hasil Peremajaan Karet Rakyat}

Banyak faktor yang mempengaruhi ketersediaan kayu karet sebagai bahan baku industri kayu karet, antara lain:

\section{Harga karet alam yang tinggi}

Pada saat harga karet meningkat, sebagian besar petani memutuskan menunda peremajaan karetnya. Sebagai contoh untuk kebun karet tua yang hanya menghasilkan $50 \mathrm{~kg}$ slab/minggu, petani masih menerima Rp 1 juta per minggu. Kondisi saat ini petani akan meremajakan kebun apabila hasil karet kurang dari $25 \mathrm{~kg}$ slab / minggu. 


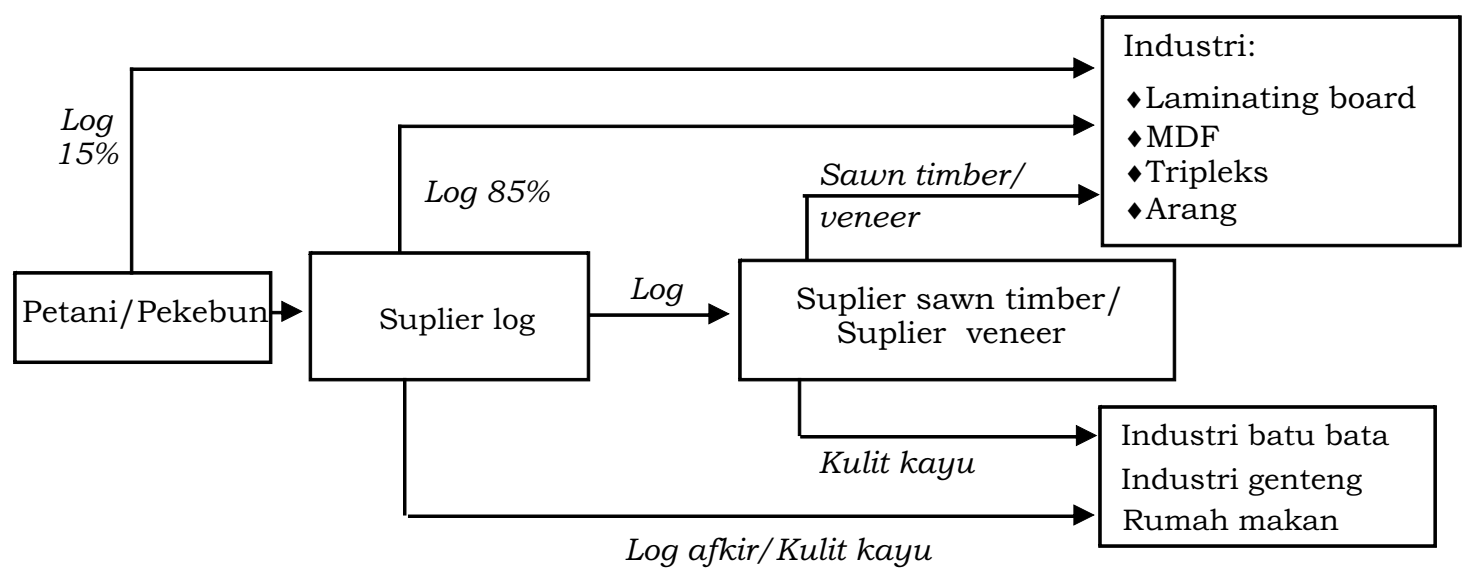

Sumber (source): Nancy et al., 2001

Gambar 2. Rantai pemasaran kayu karet

Figure 2. Marketing chain of rubberwood

Tabel 6. Penyadapan yang dilakukan petani

Table 6. Tapping practiced by smallholders

\begin{tabular}{llc}
\hline $\begin{array}{c}\text { Uraian } \\
\text { Description }\end{array}$ & & Nilai \\
& & Value \\
\hline \multirow{2}{*}{ Sistem sadap/ Tapping system (\%) } & $\mathrm{s} / 2 \mathrm{~d} / 1$ & 60 \\
& $\mathrm{~s} / 2 \mathrm{~d} / 2$ & 40 \\
\hline \multirow{2}{*}{ Arah sadapan/ Tapping direction (\%) } & Benar & 91 \\
\hline \multirow{2}{*}{ Konsumsi kulit (cm/bulan)/Bark consumption (cm/month) } & Salah & 9 \\
\hline
\end{tabular}

Sumber (source): Data Primer (Primary data)

\section{Penyadapan tidak terkendali}

Penyadapan karet umumnya dilakukan tidak terkendali, petani melakukan over tapping yang mengakibatkan kulit tanaman rusak, dan konsumsi kulit boros, sehingga umur ekonomi tanaman menjadi singkat (Tabel 6). Mutu bidang sadap yang rendah menyebabkan rendahnya rendemen kayu karet dan mutu produk yang dihasilkan.

\section{Keterbatasan jalan produksi di kebun}

Kebun karet rakyat sebagian besar terletak di pedalaman yang hanya dapat dilalui jalan setapak. Suplier adakalanya harus membuat jalan khusus untuk mengeluarkan kayu, yang tidak jarang harus meminta izin pada kebun yang bersebelahan. Masalah lain muncul apabila pengangkutan harus melewati kebun produktif dan pembeli kayu harus memberikan kompensasi yang nilainya tinggi.

\section{Faktor musim/cuaca}

Pasokan kayu karet sangat dipengaruhi oleh musim pembukaan lahan, karena petani umumnya melakukan tebas tebang pada musim kemarau (JuniSeptember). Di samping itu suplai kayu karet dipengaruhi faktor cuaca, pada musim hujan kondisi jalan di kebun umumnya rusak, sehingga kayu karet sulit untuk dikeluarkan dari kebun. Fluktuasi produksi kayu karet selama setahun ditampilkan pada Gambar 3. 


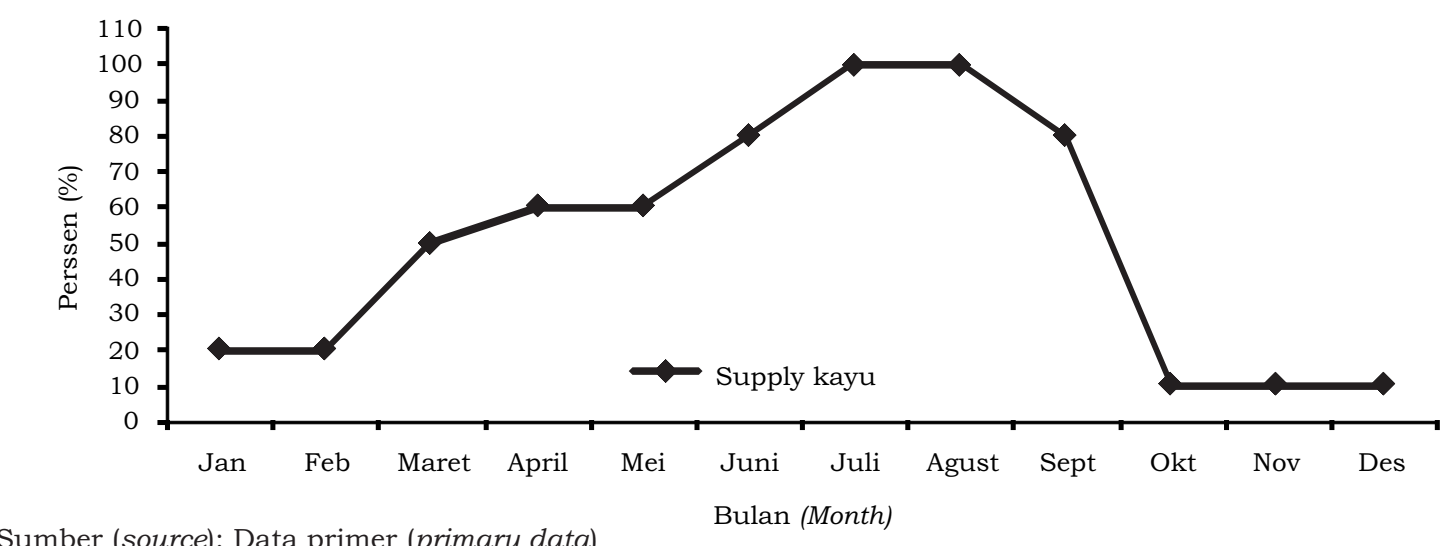

Sumber (source): Data primer (primary data)

Gambar 3. Trend suplai kayu dari perkebunan karet rakyat selama setahun

Figure 3. Yearly trend of rubberwood supply of smallholder rubber

Pada Gambar 3 terlihat bahwa pada musim kemarau yaitu Juni - September pasokan kayu sangat tinggi, dan biasanya dijadikan stok bahan baku untuk musim hujan, saat suplai kayu menurun drastis. Cadangan kayu karet untuk veneer dan MDF hanya dapat disimpan maksimal selama 3 bulan, sehingga pihak pabrik harus dapat menghitung ketersediaan kayu yang ada, agar pabrik dapat beroperasi secara berkesinambungan. Upaya yang dilakukan pihak pabrik antara lain mencampur antara stok kayu lama dan baru. Sementara ketahanan kayu karet untuk sawn timber hanya 3 hari.

Upaya yang dilakukan pabrik agar dapat tetap beroperasi pada saat suplai dari perkebunan karet rakyat merosot, adalah memasok kayu dari perkebunan besar baik perkebunan swasta maupun perkebunan milik negara yaitu PTPN, karena kebun umumnya memiliki akses jalan yang baik sehingga kayu karet masih dapat diangkut ke pabrik.

5. Pabrik kayu karet belum terdapat di semua lokasi

Nilai kayu karet sangat dipengaruhi oleh jarak dari kebun ke pabrik pengolah, karena semakin jauh, biaya transpor semakin besar dan harga kayu yang diterima pekebun semakin rendah. Radius maksimal dari kebun ke lokasi pabrik yang masih layak untuk pemasaran kayu karet adalah 200 $\mathrm{km}$. Keberadaan pabrik kayu karet masih sangat terbatas di Sumatera Selatan.
6. Pembangunan pabrik kayu karet yang terlalu berdekatan

Adanya pabrik kayu karet yang lokasinya terlalu berdekatan menimbulkan persaingan yang tidak sehat, terutama pada saat suplai kayu karet berkurang. Oleh karena itu izin pendirian pabrik kayu harus mempertimbangkan keberadaan pabrik yang telah ada. Namun pabrik kayu karet dapat juga bersinergi, misalnya pabrik MDF yang menerima kayu berdiameter $8-14 \mathrm{~cm}$, dan pabrik venneer atau sawn timber dengan diameter kayu $>15 \mathrm{~cm}$.

\section{Perijinan angkutan kayu karet}

Pengangkutan kayu karet harus memiliki SKAU (Surat Keterangan Asal Usul) yang ditandatangani Kepala Desa atau Dinas Kehutanan. Pengurusan SKAU tidak sederhana, karena harus melalui beberapa tahapan yaitu: (a) mengajukan Surat Permohonan ke Dinas Kehutanan dengan melampirkan bukti surat tanah (b) Petugas meninjau lokasi kebun yang akan diremajakan, (c) SKAU diproses. Pada SKAU tertera asal kayu (bukti kepemilikan, nomor, nama dan alamat pemilik), tujuan pengangkutan (nama dan alamat penerima), dan jumlah kayu. Setiap lembar SKAU berlaku untuk setiap truk yang mengangkut kayu karet, padahal setiap hektar kebun karet dapat menghasilkan 8 - 25 truk kayu karet. Hal ini dinilai kurang efisien, sehingga dirasakan perlunya penyederhanaan perizinan untuk pemasaran kayu yang berasal dari tanaman budidaya seperti karet. 
Upaya Memaksimalkan Pemanfaatan Kayu Karet

Saat ini upaya memaksimalkan pemanfaatan kayu karet lebih banyak dilakukan oleh pihak pabrik pengolah melalui para supliernya. Upaya yang dilakukan antara lain:

1. Memberikan insentif harga pembelian untuk asal kayu yang lokasinya jauh

Pabrik MDF memberikan insentif harga untuk karet yang berasal dari lokasi kebun yang jauh. Pada Tabel 7 terlihat bahwa pabrik MDF memberikan harga pembelian kayu yang lebih tinggi untuk lokasi yang jauh, sebagai kompensasi untuk biaya angkutan yang tinggi. Namun jarak maksimal $250 \mathrm{~km}$ dan untuk kontrol terdapat posko-posko pabrik di setiap kabupaten.

2. Membangun pabrik veneer dan sawn timber skala kecil secara terdesentralisasi

Pabrik tripleks memiliki pabrik-pabrik veneer yang terdesentralisasi di beberapa kabupaten sentra karet, sehingga dapat mengolah kayu hasil peremajaan petani karet di sekitarnya sampai pada radius 80 $\mathrm{km}$. Demikian juga industri sawn timber dapat dibangun di sentra karet, selanjutnya dipasok ke industri laminating finger joint yang lebih besar.

3. Membantu penyediaan bibit unggul karet

PT. F telah melakukan kemitraan dengan petani dalam pemanfaatan kayu karet, yaitu dengan membina dan memberi bantuan modal usaha bagi dua penangkar bibit karet. Bibit yang dihasilkan ditawarkan kepada petani yang akan meremajakan karet dan menjual kayunya ke PT. F dan selanjutnya diperhitungkan dengan nilai kayu karetnya. Di samping itu petani ditawarkan Garlon (racun tunggul) untuk mempercepat pelapukan dan mengurangi risiko tanaman terserang jamur akar putih.

4. Memberikan bantuan bibit tanaman kehutanan

Beberapa pabrik veneer memberikan bantuan bibit sengon melalui suplier (PT. C). Ada juga yang memberikan bantuan bibit jabon kepada suplier (CV. D), yaitu 10 batang bibit jabon untuk setiap $10 \mathrm{~m}^{3}$ kayu karet. Selanjutnya suplier membagikan bibit tersebut kepada petani yang lahannya diremajakan.

\section{Peran dan Dukungan Pemerintah dalam Peremajaan}

Agar program pemanfaatan kayu karet dapat dimaksimalkan diperlukan adanya dukungan pemerintah. Kekhawatiran akan terjadi penurunan produksi akibat penebangan kebun karet muda tidak pernah terjadi, karena kayu karet baru diterima pabrik setelah berumur lebih dari 20 tahun. Upaya yang telah dilakukan pemerintah dalam peremajaan antara lain:

a. Memberikan bantuan bibit unggul kepada petani karet baik melalui dana APBD maupun APBN.

b. Pemerintah telah menerapkan program Revitalisasi Perkebunan yang dituangkan dalam Peraturan Menteri Pertanian Nomor 33/Permentan/ OT.140/7/2006, yang mengatur upaya

Tabel 7. Harga beli kayu karet di tingkat pabrik, Nopember 2011

Table 7. Purchasing price of rubberwood at a factory level, November 2011

\begin{tabular}{cccc}
\hline $\begin{array}{c}\text { Produk } \\
\text { Product }\end{array}$ & $\begin{array}{c}\text { Syarat } \\
\text { Requirement }\end{array}$ & $\begin{array}{c}\text { Satuan } \\
\text { Unit }\end{array}$ & $\begin{array}{c}\text { Harga/satuan }(\mathrm{Rp}) \\
\text { Price/unit }(\mathrm{Rp})\end{array}$ \\
\hline \multirow{2}{*}{ Veneer } & Panjang $130 \mathrm{~cm}$, Diameter $>15 \mathrm{~cm}$ & $\mathrm{~m}$ & 400.000 \\
& $\begin{array}{c}\text { Panjang } 130 \mathrm{~cm} \text {, Diameter } 12-14 \mathrm{~cm} \\
\text { MDF }\end{array}$ & $\mathrm{m}$ & 250.000 \\
& Panjang $220 \mathrm{~cm}$, Diameter $>8 \mathrm{~cm}$ & ton & 350.000 \\
& jauh $(>100 \mathrm{~km})$ & ton & 250.000 \\
\hline
\end{tabular}

Sumber (source): Data Primer (Primary data) 
percepatan pengembangan perkebunan rakyat melalui usaha perluasan, peremajaan dan rehabilitasi tanaman perkebunan yang didukung kredit investasi dan subsidi bunga oleh pemerintah dengan melibatkan perusahaan di bidang usaha perkebunan sebagai mitra pengembangan dalam pembangunan kebun, pengolahan dan pemasaran (Ditjenbun, 2007).

c. Pemerintah memfasilitasi pihak swasta untuk membantu petani dalam pengembangan karet melalui program Corporate Social Responsibility (CSR).

d. Pemerintah Kabupaten Muara Enim, Provinsi Sumatera Selatan, memiliki skim kredit khusus bekerjasama dengan Bank Pembanguan Daerah yang dapat dimanfaatkan untuk membangun kebun karet, yaitu Skim Kredit MITRABUN, dengan bunga $14,5 \%$ (7,5\% ditanggung Pemda, $7 \%$ ditanggung petani) dan masa tenggang (grace period) 5 tahun.

e. Ketersediaan jalan produksi merupakan kunci utama apabila akan memanfaatkan kayu karet petani. Setiap tahun pemerintah mengalokasikan dana APBN (DAK/ Dana Alokasi Khusus) melalui Ditjen Sarana Prasarana Kementerian Pertanian dalam bentuk Bantuan Sosial (Bansos) atau BLM (Bantuan Langsung Masyarakat) untuk peningkatan jalan produksi, namun panjangnya hanya berkisar 5-15 km per kabupaten. Pengerjaan jalan umumnya dilakukan swadaya masyarakat. Bantuan perbaikan jalan produksi juga dialokasikan dari dana APBD namun jumlahnya terbatas.

\section{KESIMPULAN DAN SARAN}

Potensi kayu karet hasil peremajaan milik petani yang baru dimanfaatkan sebagai bahan baku industri kayu karet hanya sekitar $18 \%$. Ini berarti sebagian besar kayu karet belum termanfaatkan, hanya dibakar atau dibiarkan membusuk di lapangan. Apabila kayu hasil tebangan dibakar berarti menyumbang gas $\mathrm{CO}_{2} \mathrm{ke}$ udara. Di samping itu kayu karet yang membusuk di lapangan akan menjadi inang untuk berkembangnya jamur akar putih yang berbahaya bagi tanaman karet selanjutnya. Oleh karena itu perlu dilakukan upaya-upaya untuk memaksimalkan pemanfaatan kayu hasil peremajaan karet petani, di antaranya:

- Mendorong pemerintah pusat dan daerah agar meningkatkan alokasi anggaran untuk perbaikan infrastruktur jalan produksi di desa.

- Pendirian pabrik kayu karet harus mempertimbangkan pabrik yang sudah ada dan ketersediaan bahan baku lintas kabupaten, sehingga tidak terjadi persaingan yang tidak sehat untuk mendapatkan bahan baku.

- Menyederhanakan prosedur perijinan untuk penebangan dan pemasaran kayu karet.

- Pelaksanaan peremajaan karet rakyat baik proyek maupun non proyek diupayakan secara berkelompok dalam suatu hamparan sehingga lebih efisien dalam pengelolaan kayunya.

- Sosialisasi kepada para petani karet mengenai penyadapan karet yang baik dan benar, agar mutu bidang sadap menjadi lebih baik sehingga rendemen kayu karet meningkat, diikuti meningkatnya harga jual kayu. Di samping itu perlu adanya sosialisasi mengenai nilai tambah kayu karet pada saat peremajaan yang dapat dimanfaatkan untuk tambahan biaya peremajaan.

\section{DAFTAR PUSTAKA}

ANRPC. 2005. ANRPC Economic and Statistical Review. Volume 20 No. 1, June 2005. Association Natural Rubber Producing Country, Malaysia.

Direktorat Jendral Perkebunan. 2007. Perkembangan Persiapan Pelaksanaan Program Revitalisasi Perkebunan. Direktorat Jendral Perkebunan, Jakarta.

Direktorat Jenderal Perkebunan. 2009. Statistik Perkebunan Karet 20082010. Direktorat Jendral Perkebunan, Jakarta.

International Rubber Study Group (IRSG). 1995. Rubber Statistical Bulletin. International Rubber Study Group, London. 
International Rubber Study Group (IRSG). 2011. Rubber Statistical Bulletin. International Rubber Study Group, Singapore.

Malaysian Rubber Board. 2010. Natural Rubber Statistics. www.lgm.gov.my., diakses 30 November 2011.

Mustapha, Zulkifly. 1983. Some Observations on Incentive Policies in Malaysian Agriculture and Implications on Growth and Equity in The Smallholder Sector. Akademika (23), 37-64.
Nancy, C, G. Wibawa dan M. Lasminingsih. 2001. Potensi Pemanfaatan Kayu dalam Kegiatan Peremajaan Karet. Tinjauan Komiditas Perkebunan. Asosiasi Penelitian Perkebunan Indonesia dan Direktorat Jendral Perkebunan, Bogor.

Woon, W.C dan H. Norini. 2002. Trends in Malaysian Forest Policy. Policy Trends Report. Forest Research Institute Malaysia, Malaysia. 